\title{
Bisphenol A, phthalate metabolites and glucose homeostasis in healthy normal-weight children
}

\author{
Amalie Carlsson ${ }^{1,2}$, Kaspar Sørensen ${ }^{1,3}$, Anna-Maria Andersson ${ }^{1,2}$, Hanne Frederiksen ${ }^{1,2}$ and Anders Juul,2 \\ ${ }^{1}$ Department of Growth and Reproduction, Rigshospitalet, University of Copenhagen, Copenhagen, Denmark \\ ${ }^{2}$ International Research and Research Training Center in Endocrine Disruption of Male Reproduction and Child Health (EDMaRC), Copenhagen, Denmark \\ ${ }^{3}$ The Child and Youth Clinic, Rigshospitalet, University of Copenhagen, Copenhagen, Denmark \\ Correspondence should be addressed to A Juul: Anders.Juul@regionh.dk
}

\begin{abstract}
Introduction: Bisphenol A and several of the most commonly used phthalates have been associated with adverse metabolic health effects such as obesity and diabetes. Therefore, we analyzed these man-made chemicals in first morning urine samples from 107 healthy normal-weight Danish children and adolescents.

Method: This was a cross-sectional study. Participants were recruited as part of the Copenhagen Puberty Study. The subjects were evaluated by an oral glucose tolerance test (OGTT), a dual-energy X-ray absorptiometry (DXA) scan, direct oxygen uptake measurement during cycle ergometry and fasting blood samples. First morning urine was collected and phthalate metabolites and BPA were measured by liquid chromatographytandem mass spectrometry (LC-MS/MS) with prior enzymatic deconjugation. Individual chemical concentrations were divided into tertiles and analyzed in relation to biological outcome.

Results: Children in the lowest tertile of urinary BPA had significantly higher peak insulin levels during OGTT $(P=0.01)$, lower insulin sensitivity index $(P<0.01)$, higher leptin $(P=0.03)$, triglyceride $(P<0.01)$ and total cholesterol levels $(P=0.04)$, lower aerobic fitness $(P=0.02)$ and a tendency toward higher fat mass index $(P=0.1)$ compared with children in the highest tertile for UBPA. No significant differences in anthropometrics, body composition or glucose metabolism were associated with any of the phthalate metabolites measured.

Conclusion: This pilot study on healthy normal-weight children suggests an inverse association between BPA and insulin resistance. Our findings contrast other crosssectional studies showing a positive association for BPA, which may be due to confounding or reverse causation because diet is an important source of both BPA exposure and obesity.
\end{abstract}

Key Words

- endocrine-disrupting chemicals

- children

- OGTT

- obesity

- diabetes
Endocrine Connections (2018) 7, 232-238

\section{Introduction}

Concerns have been raised that man-made chemicals such as phthalates and bisphenol A (BPA) may have endocrine properties in humans. These potential endocrine disruptive chemicals (EDCs) are widely used in modern societies, and the majority of the human population is exposed to several of these environmental chemicals daily (1).

http://www.endocrineconnections.org https://doi.org/10.1530/EC-17-0344

(c) 2018 The authors Published by Bioscientifica Ltd
BPA is an estrogenic high-volume chemical used as the base compound in the manufacturing of polycarbonated plastics and epoxy resins, which are used for a variety of plastic products and barrier coatings for the inner surfaces of food and beverage cans (2). Humans are primarily exposed to BPA through ingestion (3). Urinary

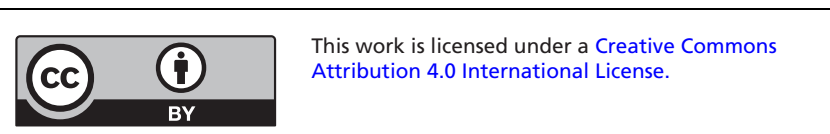


Table 1 Basic characteristic of the 107 subjects included in

BPA excretion has been positively associated with higher prevalence of diabetes (4) and obesity (5) in adults and obesity (6) in children.

Phthalates are used as softeners in PVC plastics. As phthalates are continuously emitted from PVC, humans can be exposed through ingestion, inhalation or by dermal contact (7). Serious adverse health effects have been associated with high phthalate exposure such as alteration in reproductive development and increased risks of insulin resistance and obesity in human adults $(8,9$, $10,11,12)$. Importantly, children may be at increased risk of exposure as phthalates are used in the manufacturing of many industrial products such as toys, building materials and food packaging (7). Despite increased regulations regarding the use of phthalates in children's toys, detectable measures of phthalate metabolites are still being found in $97 \%$ of the childhood population (1). The exposure to phthalates has been associated with increased risk of obesity in childhood, but data are equivocal $(6,13$, 14). As for BPA, human data on effects of phthalates on insulin sensitivity are still lacking.

In the present study, urinary excretion of BPA and metabolites of the most commonly used phthalates in 107 healthy normal-weight Danish children were associated to fasting lipids, leptin and adiponectin levels as well as to glucose and insulin levels during a two-h oral glucose tolerance test (OGTT).

\section{Methods \\ Participants}

Subjects were recruited as part of the Copenhagen Puberty Study $(15,16)$ from primary schools in the Copenhagen community. A total of 107 healthy Caucasian children (58 girls) aged 8.5-16.1 years volunteered. Characteristics of the children are specified in Table 1 . All participants had total body fat and lean mass evaluated with a wholebody dual-energy X-ray absorptiometry (DXA) scan using a CDR 1000/W densitometer (Hologic, Bedford, MA, USA) with software, version 6.2. Fat mass index was calculated as total fat mass divided by height squared. Aerobic fitness was evaluated by assessing maximal oxygen uptake $\left(\mathrm{V}_{\mathrm{O} 2} \max \right)$ during a cycle ergometry test using an electronically braked cycle ergometer (Ergomedic 839: Monark, Varberg, Sweden). $\mathrm{V}_{\mathrm{O} 2} \max$ was measured directly using an online pulmonary gas analyzer system (Quark CPET; Cosmed, Rome, Italy). Data on OGTT, body composition as well as other aspects have previously been the study.

\begin{tabular}{|c|c|c|}
\hline & Boys $(n=49)$ & Girls $(n=58)$ \\
\hline BMI $\left(\mathrm{kg} / \mathrm{m}^{2}\right)$ & $18.07(15.0-26.1)$ & $18(14.4-28.3)$ \\
\hline $\begin{array}{l}\text { Fat mass index } \\
\left(\mathrm{kg} / \mathrm{m}^{2}\right)\end{array}$ & $3.2(1.4-6.8)$ & $3.6(2.0-9.0)$ \\
\hline $\begin{array}{l}\text { Fasting glucose } \\
(\mathrm{mmol} / \mathrm{L})\end{array}$ & $4.9(3.9-5.9)$ & $4.8(3.2-5.4)$ \\
\hline $\begin{array}{l}\text { 2-h glucose } \\
(\mathrm{mmol} / \mathrm{L})\end{array}$ & 5. $1(3-7.3)$ & $5.1(3.3-7.3)$ \\
\hline $\begin{array}{l}\text { Fasting insulin } \\
(\mathrm{pmol} / \mathrm{L})\end{array}$ & $42(10-102)$ & $50(11-168)$ \\
\hline $\begin{array}{l}\text { Peak insulin } \\
(\mathrm{mmol} / \mathrm{L})\end{array}$ & $352(112-1004)$ & $407(150-1329)$ \\
\hline $\begin{array}{l}\text { Triglycerides } \\
\text { (mmol/L) }\end{array}$ & $0.6(0.4-1.7)$ & $0.8(0.4-2.0)$ \\
\hline $\mathrm{HDL}(\mathrm{mmol} / \mathrm{L})$ & $1.5(1.1-2.1)$ & $1.5(0.7-2.2)$ \\
\hline LDL (mmol/L) & $2.1(0.5-3.2)$ & $2.3(0.8-3.8)$ \\
\hline $\begin{array}{l}\text { Total cholesterol } \\
(\mathrm{mmol} / \mathrm{L})\end{array}$ & $3.6(2.5-4.6)$ & $3.7(2.6-5.6)$ \\
\hline Leptin (ng/mL) & 3987 (884-37065) & 6549 (1772-49495) \\
\hline $\begin{array}{l}\text { Adiponectin } \\
(\mu \mathrm{g} / \mathrm{mL})\end{array}$ & $24532.5(12100-57085)$ & $27320(9375-60190)$ \\
\hline $\begin{array}{l}\mathrm{V}_{\mathrm{O} 2} \max \\
(\mathrm{mL} / \mathrm{kg} / \mathrm{min})\end{array}$ & $46.7(30.3-63.2)$ & $40.3(25.1-49.3)$ \\
\hline
\end{tabular}

Data are expressed as medians and range.

published $(17,18)$. The study was approved by the local ethics committee (reference no. KF 01282214 and KF 11 2006-2033). Consent has been obtained from each patient or subject after full explanation of the purpose and nature of all procedures used.

\section{Blood sampling}

Venous fasting blood samples were drawn after $12 \mathrm{~h}$ of fasting from the ante-cubital vein into standard vacuum tubes and centrifuged $(3000 \boldsymbol{g}$ at $10 \mathrm{~min})$ within $30 \mathrm{~min}$. Plasma was immediately stored at $-20^{\circ} \mathrm{C}$ until analysis. A standard two-h OGTT with an oral glucose load of $1.75 \mathrm{~g}$ of glucose per kilogram bodyweight (maximum $75 \mathrm{~g}$ glucose) was performed for all subjects. Blood samples were drawn with 30-min intervals for determination of glucose and insulin levels. Insulin sensitivity index a.m. Matsuda was calculated. In addition, fasting leptin, adiponectin and lipid profiles (triglyceride, total cholesterol and high- and low-density lipoproteins) were determined as previously described (17).

\section{Urine sample collection and chemical analysis}

Each of the participants collected two consecutive first morning urine samples and one 24-h urine sample. All samples were collected in November 2007 and have

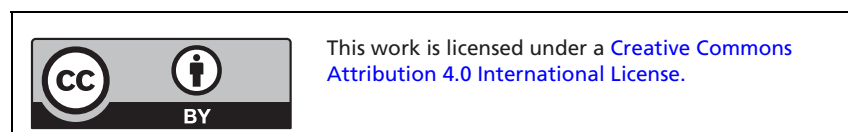


previously been analyzed for the content of metabolites of the most common phthalate diesters; diethyl phthalate (DEP), di-n-butyl phthalate (DnBP), di-iso-butyl phthalate (DiBP), butylbenzyl phthalate BBzP, di-(2-ethyl-hexyl) phthalate (DEHP) and di-iso-nonyl phthalate (DiNP) and BPA as one out of nine environmental phenols measured by liquid chromatography-tandem mass spectrometry (LC-MS/MS) with prior enzymatic deconjugation $(19,20)$.

For the present study, first morning urine collected from the first of the two consecutive mornings was used.

\section{Data analysis}

The volume of urine was determined by converting the weight in grams of the collected urine into milliliters, as the urinary density is close to $1 \mathrm{~g} / \mathrm{mL}$ (varies between 1.003 and $1.035 \mathrm{~g} / \mathrm{mL}$ ). Urinary concentrations of phthalate metabolites $(\mathrm{ng} / \mathrm{mL})$ were measured and converted to absolute amount excreted ( $\mu$ g per first morning urine sample) by multiplying the urinary concentration in each sample with the urine volume $(\mathrm{mL})$.

The metabolite concentration $(\mathrm{ng} / \mathrm{mL})$ of DiBP and DnBP were summed $\left(\sum \mathrm{MBP}_{(\mathrm{i}+\mathrm{n})}\right)$ and in order to combine the phthalate metabolites with different molecular weight, the amount of each metabolite was converted into molar concentration, summed in groups and backconverted into $\mathrm{ng} / \mathrm{mL}$ by multiplying with the molecular weight of DEHP for the sums of four DEHP metabolites ( $\left.\sum \mathrm{DEHPm}\right)$ and the molecular weight of DiNP for the sums of four DiNP metabolites ( $\sum$ DiNPm). The molar sum of all measured phthalate metabolites ( $\sum$ all phth.m) were not back-converted but expressed in $\mu \mathrm{M}$.

\section{Statistics}

Urinary BPA, monoethyl phthalate (MEP), $\sum \mathrm{MBP}_{(\mathrm{i}+\mathrm{n})}$, monobenzyl phthalate (MBzP), $\sum$ DEHPm, $\sum$ DiNPm and $\sum$ all phth.m were log-transformed to assure a Gaussian distribution. Correlations between the summed phthalates and BPA levels were evaluated by Pearson Correlations.

The compounds were divided into tertiles allowing children with urinary excretion levels below the limit of detection (LOD) to be included. Differences in metabolic parameters between tertiles were evaluated by independent Student $t$-tests. Peak insulin levels, insulin sensitivity index, triglyceride levels, fat mass index and leptin levels were all log-transformed before analyses. Univariate ANOVAs (general linear models) were used for adjusted analyses with sex and pubertal stage (3 groups: pre-pubertal, breast/genital stage 2-3 and breast/genital
Table 2 Potential confounders divided into the BPA tertiles.

\begin{tabular}{|c|c|c|c|}
\hline & Low $(n=35)$ & $\begin{array}{c}\text { Medium } \\
(n=35)\end{array}$ & High $(n=37)$ \\
\hline $\begin{array}{l}\text { Boys/Girls } \\
(n)\end{array}$ & $16 / 19$ & $16 / 19$ & $17 / 20$ \\
\hline Age (years) & $12.3(8.7-15.4)$ & $\begin{array}{c}12.4 \\
(8.5-15.4)\end{array}$ & $12.3(8.7-16.1)$ \\
\hline $\begin{array}{l}\text { Puberty } \\
\text { (stage*) }\end{array}$ & $8 ; 13 ; 14$ & $7 ; 12 ; 16$ & $12 ; 11 ; 14$ \\
\hline BPA (ng/mL) & $1.03(<$ LOD-1.74) & $\begin{array}{c}2.55 \\
(1.38-4.11)\end{array}$ & $6.83(3.82-17.32$ \\
\hline
\end{tabular}

*Breast/genital stage l; breast/genital stage 2-3; breast/genital stage 4-5.

stage 4-5) included as fixed variable and age as continuous variable. No significant interactions were found between sex and puberty in any of the reported models except for insulin sensitivity for which the results of the combined as well as the sex-specific analyses is shown. Potential confounders divided into BPA tertiles are shown in Table 2. All statistical analyses were done using the statistical software IBM SPSS, version 23.0.

\section{Results}

In total, 107 children were included in the analyses. One-hundred and four children (55 girls) completed a full 2-h glucose tolerance test, and aerobic fitness levels were available in 91 (48 girls). Basic characteristics of all children are shown in Table 1 . None of the children had an abnormal glucose tolerance test. Eight children (5 girls) had urinary BPA below LOD $(<0.12 \mathrm{ng} / \mathrm{mL})$. Median and range of values of measured phthalate metabolites

Table 3 Levels of measured phthalate metabolites and BPA in the 107 children and adolescents included in the study.

\begin{tabular}{|c|c|c|c|}
\hline & $n$ & Median & Range \\
\hline MEP (ng/mL) & 107 & 46.822542 & $3.6893-658.24$ \\
\hline MBP (ng/mL) & 107 & 190.09819 & 48.1209-713.1561 \\
\hline $\mathrm{MBzP}(\mathrm{ng} / \mathrm{mL})$ & 107 & 32.930963 & $3.0639-451.7129$ \\
\hline$\sum D E H P(n g / m L)$ & 107 & 167.5 & 50.5-771.5 \\
\hline$\sum \operatorname{DiNP}(\mathrm{ng} / \mathrm{mL})$ & 107 & 31.1 & 6.6-673.3 \\
\hline $\begin{array}{l}\sum \text { corr Phth.m } \\
(\mu \mathrm{M})(\mathrm{nmol} / \mathrm{mL})\end{array}$ & 107 & 2.054935 & $0.583-5.5409$ \\
\hline $\begin{array}{l}\sum \text { alll Phth.m } \\
(\mu \mathrm{M})(\mathrm{nmol} / \mathrm{mL})\end{array}$ & 107 & 1.627242 & $0.4334-5.0396$ \\
\hline BPA (ng/mL) & 107 & 2.76 & <LOD-17.32 \\
\hline BP-3 (ng/mL) & 107 & 1.484424 & $<$ LOD-136.4388 \\
\hline$\sum D C P(n g / m L)$ & 107 & 0.93621 & <LOD-23.3397 \\
\hline
\end{tabular}

BPA, bisphenol A; MEP, monoethyl phthalate; MBP, monobutyl phthalate isomers; MBzP, monobenzyl phthalate; $\sum$ DEHPm, sum of DEHP metabolites; $\sum$ DiNPm, sum of DiNP metabolites; $\sum$ all phth.m, sum of all phthalate metabolites (MEP, MiBP, MnBP, MBzP and metabolites of DEHP and DiNP).

This work is licensed under a Creative Commons Attribution 4.0 International License. 
BPA

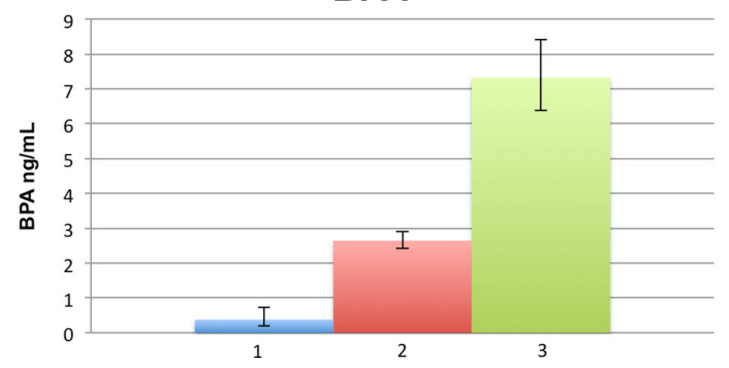

Insulin sensitivity index

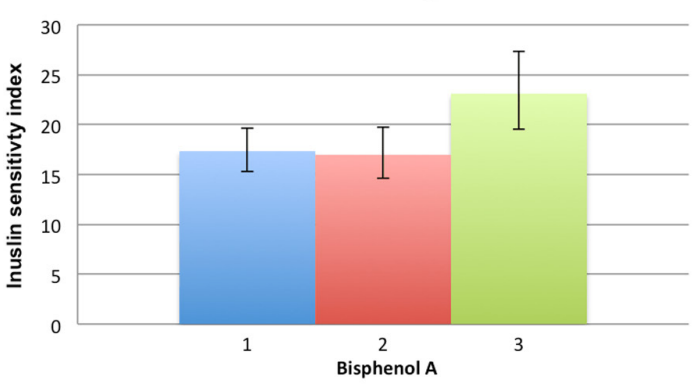

Aerobic fitness

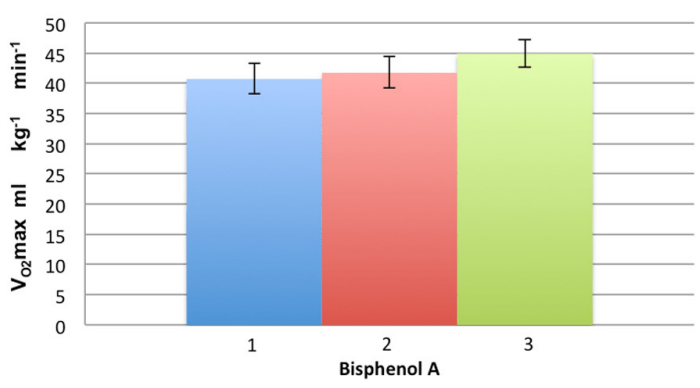

Fatmassindex

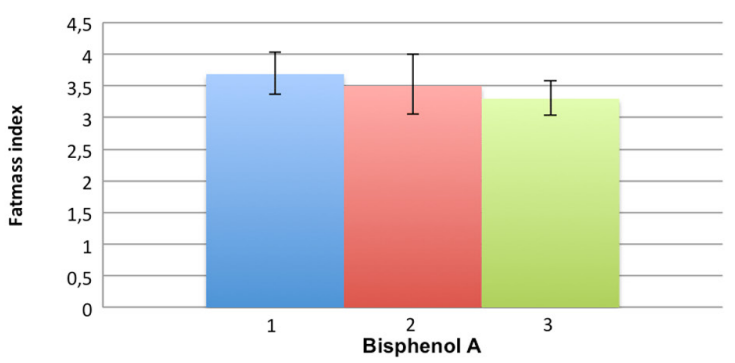

Peak insulin

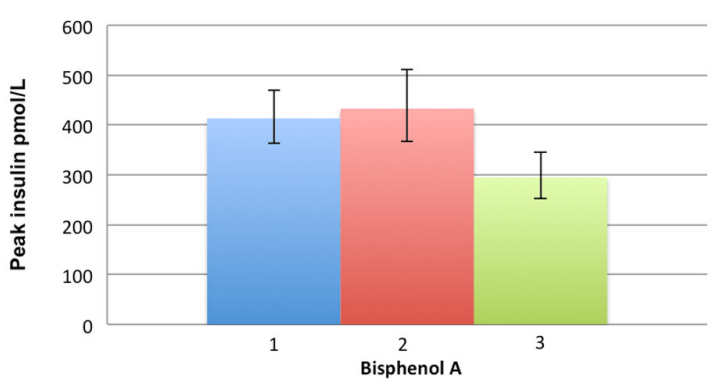

Leptin

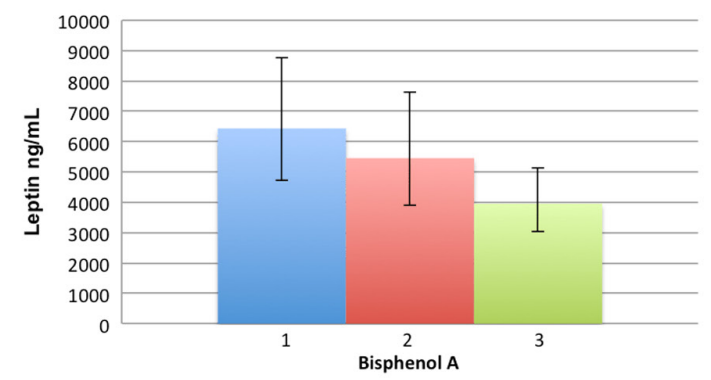

Figure 1

Bisphenol A (BPA) tertiles and the distribution of selected metabolic parameters within BPA tertiles.

and BPA are shown in Table 3. All phthalate metabolites were positively correlated $(r>0.35 ; P<0.01)$. BPA did not correlate with neither of the measured phthalate levels $(r<0.08 ; P>0.43)$.

The lowest tertile of BPA had significantly higher peak insulin levels during OGTT $(P=0.01)$, lower insulin sensitivity index $(P<0.01)$, higher leptin $(P=0.03)$, triglyceride $(P<0.01)$ and total cholesterol levels $(P=0.04)$, lower aerobic fitness $(P=0.02)$ and a tendency toward higher fat mass index $(P=0.1)$ compared with the highest tertile for BPA (Fig. 1). No differences were found for adiponectin or lipoprotein levels between the BPA tertiles (all $P>0.2$ ). Sex, age and pubertal development were equally distributed among tertiles $(P>0.4)$. Adjusted for sex, age and pubertal development, the highest BPA tertile was still significantly associated with lower peak insulin levels (28.7\% (5.1-57.5), $P=0.02)$, higher insulin

$$
\text { http://www.endocrineconnections.org }
$$

sensitivity index $(22.1 \%(2.2-45.8), P=0.03)$ and lower triglyceride levels $(25.4 \%(5.5-48.9), P=0.03)$ compared with the lowest BPA tertile (ANOVA). Due to the significant interaction between sex and pubertal development for insulin sensitivity index, sex-specific analyses were done. Although none of these analyses were significant, the parameter estimates were similar to the combined analysis (boys: $19.8 \%$ ( -6.0 to 52.7$), P=0.14$; girls: $(26.5 \%$ ( -2.6 to 64.4), $P=0.08)$ ). Additional adjustment for fat mass index did not change any of the results in the adjusted analyses (not shown). In adjusted analyses, no associations were found between BPA tertile and fat mass index or fitness levels, respectively $(P>0.16)$.

No significant differences in anthropometrics, body composition or glucose metabolism were found between tertiles of any of the phthalates measured (results not shown). 


\section{Discussion}

In this clinical study of healthy normal-weight children, urinary BPA and phthalate metabolites were present in detectable levels in the majority of urine samples, but no association was found between current exposure to these chemicals and adverse effect on body composition or glucose metabolism. On the contrary, we found that the group of children with the highest urinary excretion of BPA had significantly lower glucose-stimulated peak insulin levels, better insulin sensitivity and lower triglyceride levels compared with the lowest exposed children. These results were independent of adiposity.

It is well documented that the general population and children in particular are exposed to manufactured chemicals such as phthalates and BPA $(1,21)$. The more important question is whether these exposures form a relevant health risk. The hypothesis that exposure to these chemicals during childhood predispose to obesity and metabolic disease is far from verified $(5,6,22)$.

To shed more light on this issue, we aimed to evaluate the dynamics in glucose and insulin during a standard OGTT in relation to current BPA and phthalate exposure. We conducted a thorough body compositional and metabolic examination of 107 healthy children with concomitant determination of urinary excretion of BPA and phthalate levels in full morning urine.

Our present findings that the group of children with the highest BPA levels had better insulin sensitivity and lower triglyceride levels is contradictive to most previous studies in children $(6,23)$ and do not support that concurrent BPA exposure has adverse effects on glucose homeostasis. However, due to the cross-sectional design of the present study, the temporal cause-and-effect relationship could not be determined. The fact that higher BPA exposure should have a positive influence on glucose metabolism seems unlikely. Thus, reverse causality - that the children with the healthier and more active lifestyle were more exposed to BPA. This could hypothetically be through consumption of more food and drinks contained in BPA-coated packaging to compensate for the higher energy expenditure of the more active lifestyle.

Previous cross-sectional studies showing higher prevalence of obesity and diabetes in adults $(4,5,24,25)$ and obesity in children (23) with higher BPA exposure may also be due to reverse causality. Exposure to BPA is mainly through intake of food and drinks contained in BPA-coated packaging - and exposure to BPA will therefore on average be higher with higher caloric intake. Thus, high BPA excretion may simply be a biomarker for intake of excess calories in these studies. To avoid this confounding, detailed and reliable data on the dietary sources of BPA exposure, calorie intake and energy expenditure such as physical activity is of paramount importance and have not been taken into account in previous studies.

While human studies are conflicting regarding the potential harmful effect of BPA on metabolism, experimental rodent studies show a more consistent pattern of BPA having adverse effects on the metabolic system, though the exact effect of BPA is yet to be determined. In mice that received a high-fat diet, BPA exposure was associated with more severe insulin resistance (26) and increased body weight and fat mass (27). Another study found that BPA did not induce body weight or fat mass but was instead disrupting glucose homeostasis, and this in fact was aggravated by a high-fat diet (28). Altogether, this could suggest that high doses of BPA may have an independent role in promoting obesity and/or insulin resistance in mice - though it is important to note, that in these experimental studies, the rodents are treated with about a thousand times greater dose of BPA compared to the exposure of the children in our clinical study.

It has been suggested that the harmful effect of BPA may be limited to a window of susceptibility, proposing that prenatal exposure in children (29) or exposure during pregnancy (30) may have long-term deleterious consequences in mice. However, no human data are available to confirm these suggestions. We evaluated current exposure levels with current body composition and glucose metabolism in children and adolescents and found no evidence that current exposure of these metabolites has an harmful effect on body composition or glucose metabolism at the time of exposure in healthy children, though further investigation is needed to prove of any long-term effects.

The lack of solid human data to confirm the results from the experimental models still renders the question if BPA has adverse effects on body composition and glucose metabolism in humans unanswered. Prospective studies with repeated measurement of BPA and metabolic risk profiling are needed before firm conclusion can be made.

An association between phthalate exposure and obesity has been suggested, but controversy exists. One study based on NHANES data showed a positive association between urinary levels of some phthalates and waist circumference in men but not in women (10). A study on the Swedish population showed the same, though the

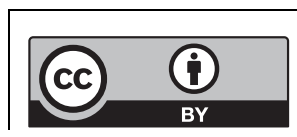

This work is licensed under a Creative Commons Attribution 4.0 International License. 
association was only seen in women but not in men (31). Similarly, no consistent pattern is evident when assessing associations between phthalates and diabetes or markers of glucose metabolism $(8,32,33)$. These inconsistencies could be due the same abovementioned reasons - the existence of reverse causality and the lack of dietary source of phthalate exposure. In the present study, no associations were found between phthalate exposure and either adiposity or glucose metabolism.

The strength of this investigation is the unselected sample of 107 well-characterized children. The primary limitation of this study is its small size, and the crosssectional design, which cannot show the temporal pattern of exposure and disease. Furthermore, our study population consists of healthy and normal-weight children, and we may therefore not have been able to observe the associations presented in other studies including overweight and obese subjects. In addition, since these chemicals do not persist in vivo, a first morning urine sample will only be suggestive of exposure for the previous day and may not give an accurate measure of long-term exposure. A high intra-individual day-to-day variation in urinary BPA excretion exists (34), which may lead to risk of exposure misclassification.

\section{Conclusion}

In conclusion, our study on healthy, normal-weight children do not support that current exposure to phthalates and bisphenols is associated with adverse effects on insulin resistance or adiposity. Other crosssectional studies showing positive association between BPA and obesity might be confounded by lack of data on caloric intake and energy expenditure. However, studies on murine models continue to show adverse health effect. Therefore, further prospective studies with serial measurements of the chemicals of interest, detailed measures of nutrient intake and energy expenditure, as well as long-term follow-up are greatly warranted.

\section{Declaration of interest}

The authors declare that there is no conflict of interest that could be perceived as prejudicing the impartiality of the research reported.

\section{Funding}

Research Fund of Capital Region of Copenhagen; Research Fund of Rigshospitalet; Kirsten og Freddy Johansen Foundation.

\section{Consent}

Consent has been obtained from each patient or subject after full explanation of the purpose and nature of all procedures used.

\section{Acknowledgment}

The authors are grateful to Ole Nielsen and Stine E Andersen for their skilled technical assistance and to all the healthy children who participated in the Copenhagen Puberty Study.

\section{References}

1 Frederiksen H, Jensen TK, Jørgensen N, Kyhl HB, Husby S, Skakkebæk NE, Main KM, Juul A \& Andersson AM. Human urinary excretion of non-persistent environmental chemicals: an overview of Danish data collected between 2006 and 2012. Reproduction 2014 147 555-565. (https://doi.org/10.1530/REP-13-0522)

2 Rubin BS. Bisphenol A: an endocrine disruptor with widespread exposure and multiple effects. Journal of Steroid Biochemistry and Molecular Biology 2011127 27-34. (https://doi.org/10.1016/j. jsbmb.2011.05.002)

3 Morgan MK, Jones PA, Calafat AM, Ye X, Croghan CW, Chuang JC, Wilson NK, Clifton MS, Figueroa Z \& Sheldon LS. Assessing the quantitative relationships between preschool children's exposures to bisphenol A by route and urinary biomonitoring. Environmental Science and Technology 201145 5309-5316. (https://doi.org/10.1021/ es200537u)

4 Sabanayagam C, Teppala S \& Shankar A. Relationship between urinary bisphenol A levels and prediabetes among subjects free of diabetes. Acta Diabetologica 201350 625-631. (https://doi. org/10.1007/s00592-013-0472-z)

5 Shankar A, Teppala S \& Sabanayagam C. Urinary bisphenol a levels and measures of obesity: results from the national health and nutrition examination survey 2003-2008. ISRN Endocrinology 2012 2012 965243. (https://doi.org/10.5402/2012/965243)

6 Trasande L, Attina TM \& Blustein J. Association between urinary bisphenol A concentration and obesity prevalence in children and adolescents. JAMA 2012308 1113-1121. (https://doi. org/10.1001/2012.jama.11461)

7 Wittassek M, Koch HM, Angerer J \& Brüning T. Assessing exposure to phthalates - the human biomonitoring approach. Molecular Nutrition and Food Research 201155 7-31. (https://doi.org/10.1002/ mnfr.201000121)

8 Lind PM, Zethelius B \& Lind L. Circulating levels of phthalate metabolites are associated with prevalent diabetes in the elderly. Diabetes Care 201235 1519-1524. (https://doi.org/10.2337/dc112396)

9 Hatch EE, Nelson JW, Qureshi MM, Weinberg J, Moore LL, Singer M \& Webster TF. Association of urinary phthalate metabolite concentrations with body mass index and waist circumference: a cross-sectional study of NHANES data, 1999-2002. Environmental Health 20087 27. (https://doi.org/10.1186/1476-069X-7-27)

10 Stahlhut RW, van Wijngaarden E, Dye TD, Cook S \& Swan SH. Concentrations of urinary phthalate metabolites are associated with increased waist circumference and insulin resistance in adult U.S. males. Environmental Health Perspectives 2007115 876-882. (https:// doi.org/10.1289/ehp.9882)

11 Kay VR, Bloom MS \& Foster WG. Reproductive and developmental effects of phthalate diesters in males. Critical Reviews in Toxicology 201444 467-498. (https://doi.org/10.3109/10408444.2013.875983)

12 Kay VR, Chambers C \& Foster WG. Reproductive and developmental effects of phthalate diesters in females. Critical Reviews in Toxicology 201343 200-219. (https://doi.org/10.3109/104 08444.2013.766149)

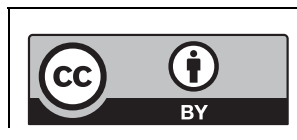

This work is licensed under a Creative Commons Attribution 4.0 International License. 
13 Teitelbaum SL, Mervish N, Moshier EL, Vangeepuram N, Galvez MP, Calafat AM, Silva MJ, Brenner BL \& Wolff MS. Associations between phthalate metabolite urinary concentrations and body size measures in New York City children. Environmental Research 2012112 186-193. (https://doi.org/10.1016/j.envres.2011.12.006)

14 Buser MC, Murray HE \& Scinicariello F. Age and sex differences in childhood and adulthood obesity association with phthalates: analyses of NHANES 2007-2010. International Journal of Hygiene and Environmental Health 2014217 687-694. (https://doi.org/10.1016/j. ijheh.2014.02.005)

15 Aksglaede L, Sørensen K, Petersen JH, Skakkebaek NE \& Juul A. Recent decline in age at breast development: the Copenhagen Puberty Study. Pediatrics 2009123 e932-e939. (https://doi. org/10.1542/peds.2008-2491)

16 Sørensen K, Aksglaede L, Petersen JH \& Juul A. Recent changes in pubertal timing in healthy Danish boys: associations with body mass index. Journal of Clinical Endocrinology and Metabolism 201095 263-270. (https://doi.org/10.1210/jc.2009-1478)

17 Sørensen K, Aksglaede L, Munch-Andersen T, AachmannAndersen NJ, Petersen JH, Hilsted L, Helge JW \& Juul A. Sex hormone-binding globulin levels predict insulin sensitivity, disposition index, and cardiovascular risk during puberty. Diabetes Care 200932 909-914. (https://doi.org/10.2337/dc08-1618)

18 Bisgaard A, Sørensen K, Johannsen TH, Helge JW, Andersson AM $\&$ Juul A. Significant gender difference in serum levels of fibroblast growth factor 21 in Danish children and adolescents. International Journal of Pediatric Endocrinology 20142014 7. (https://doi. org/10.1186/1687-9856-2014-7)

19 Frederiksen H, Aksglaede L, Sorensen K, Skakkebaek NE, Juul A \& Andersson AM. Urinary excretion of phthalate metabolites in 129 healthy Danish children and adolescents: estimation of daily phthalate intake. Environmental Research 2011111 656-663. (https:// doi.org/10.1016/j.envres.2011.03.005)

20 Frederiksen H, Aksglaede L, Sorensen K, Nielsen O, Main KM, Skakkebaek NE, Juul A \& Andersson AM. Bisphenol A and other phenols in urine from Danish children and adolescents analyzed by isotope diluted TurboFlow-LC-MS/MS. International Journal of Hygiene and Environmental Health 2013216 710-720. (https://doi. org/10.1016/j.ijheh.2013.01.007)

21 Centers for Disease Control and Prevention. Fourth National Report on Human Exposure to Environmental Chemicals, updated Tables, February 2015. Atlanta, GA, USA: CDC, 2015. (available at: https:// www.cdc.gov/biomonitoring/pdf/fourthreport_updatedtables_ feb2015.pdf)

22 Sharpe RM \& Drake AJ. Obesogens and obesity - an alternative view? Obesity 201321 1081-1083. (https://doi.org/10.1002/oby.20373)

23 Shankar A \& Teppala S. Relationship between urinary bisphenol A levels and diabetes mellitus. Journal of Clinical Endocrinology and Metabolism 201196 3822-3826. (https://doi.org/10.1210/jc.2011-1682)

24 Lang IA, Galloway TS, Scarlett A, Henley WE, Depledge M, Wallace RB \& Melzer D. Association of urinary bisphenol A concentration with medical disorders and laboratory abnormalities in adults. JAMA 2008300 1303-1310. (https://doi.org/10.1001/ jama.300.11.1303)

25 Eng DS, Lee JM, Gebremariam A, Meeker JD, Peterson K \& Padmanabhan V. Bisphenol A and chronic disease risk factors in US children. Pediatrics 2013132 e637-e645. (https://doi.org/10.1542/ peds.2013-0106)

26 Moon MK, Jeong IK, Jung Oh T, Ahn HY, Kim HH, Park YJ, Jang HC \& Park KS. Long-term oral exposure to bisphenol A induces glucose intolerance and insulin resistance. Journal of Endocrinology 2015226 35-42. (https://doi.org/10.1530/JOE-14-0714)

27 Yang M, Chen M, Wang J, Xu M, Sun J, Ding L, Lv X, Ma Q, Bi Y, Liu R, et al. Bisphenol A promotes adiposity and inflammation in a nonmonotonic dose-response way in 5-week-old male and female C57BL/6J mice fed a low-calorie diet. Endocrinology $2016 \mathbf{1 5 7}$ 2333-2345. (https://doi.org/10.1210/en.2015-1926)

28 Ding S, Fan Y, Zhao N, Yang H, Ye X, He D, Jin X, Liu J, Tian C, Li H, et al. High-fat diet aggravates glucose homeostasis disorder caused by chronic exposure to bisphenol A. Journal of Endocrinology 2014221 167-179. (https://doi.org/10.1530/JOE-13-0386)

29 Watkins DJ, Peterson KE, Ferguson KK, Mercado-García A, Tamayo y Ortiz M, Cantoral A, Meeker JD \& Téllez-Rojo MM. Relating phthalate and BPA exposure to metabolism in peripubescence: the role of exposure timing, sex, and puberty. Journal of Clinical Endocrinology and Metabolism 2016101 79-88. (https://doi. org/10.1210/jc.2015-2706)

30 Alonso-Magdalena P, García-Arévalo M, Quesada I \& Nadal Á. Bisphenol-A treatment during pregnancy in mice: a new window of susceptibility for the development of diabetes in mothers later in life. Endocrinology 2015156 1659-1670. (https://doi.org/10.1210/ en.2014-1952)

31 Lind PM, Roos V, Rönn M, Johansson L, Ahlström H, Kullberg J \& Lind L. Serum concentrations of phthalate metabolites are related to abdominal fat distribution two years later in elderly women. Environmental Health 201211 21. (https://doi.org/10.1186/1476069X-11-21)

32 Svensson K, Hernández-Ramírez RU, Burguete-García A, Cebrián ME, Calafat AM, Needham LL, Claudio L \& López-Carrillo L. Phthalate exposure associated with self-reported diabetes among Mexican women. Environmental Research 2011111 792-796. (https://doi. org/10.1016/j.envres.2011.05.015)

33 James-Todd T, Stahlhut R, Meeker JD, Powell SG, Hauser R, Huang T $\&$ Rich-Edwards J. Urinary phthalate metabolite concentrations and diabetes among women in the National Health and Nutrition Examination Survey (NHANES) 2001-2008. Environmental Health Perspectives 2012120 1307-1313. (https://doi.org/10.1289/ ehp.1104717)

34 Lassen TH, Frederiksen H, Jensen TK, Petersen JH, Main KM, Skakkebæk NE, Jørgensen N, Kranich SK \& Andersson AM. Temporal variability in urinary excretion of bisphenol A and seven other phenols in spot, morning, and 24-h urine samples. Environmental Research 2013126 164-170. (https://doi.org/10.1016/j. envres.2013.07.001)

Received in final form 14 November 2017

Accepted 13 December 2017

Accepted Preprint published online 13 December 2017 http://www.endocrineconnections.org https://doi.org/10.1530/EC-17-0344
(C) 2018 The authors Published by Bioscientifica Ltd

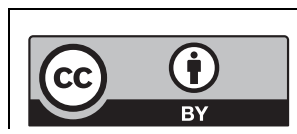

This work is licensed under a Creative Commons Attribution 4.0 International License. 